\title{
Cell Wall Formation in the Saprolegniales: Cytoplasmic Vesicles Underlying Developing Walls
}

\author{
By I. B. HEATH*, J. L. GAY AND A. D. GREENWOOD \\ Department of Botany and Plant Technology, Imperial College, Prince Consort Road, \\ London S.W.7
}

(Accepted for publication 22 December 1970)

\begin{abstract}
SUMMARY
Wall formation at different stages in the life-cycle of members of the Saprolegniales is accompanied by formation of membrane-bounded vesicles concentrated in the adjacent cytoplasm. The staining characteristics of these vesicles varies with the fixative used but suggest that their contents are intermediate between those of the Golgi cisternae and the cell walls. The origin and function of the vesicles are discussed.
\end{abstract}

\section{INTRODUCTION}

Recent ultrastructural investigations have revealed an accumulation of small vesicles in vegetative hyphal apices from diverse genera of fungi (Brenner \& Carroll, 1968; McClure, Park \& Robinson, I968; Girbardt, I969; Hemmes \& Hohl, 1969; Grove, Bracker \& Morré, 1970). It seems likely that these vesicles are involved in the formation of hyphal walls but their origin and contents remain uncertain. The easily manipulated phases of growth of Saprolegnia and Dictyuchus species provide an opportunity to study the initiation and cessation of wall synthesis in a discontinuous series. This work aims to provide a more comprehensive account of the structures involved in wall formation at both the vegetative apices and other growing stages in the life-cycle, and to provide information on the origin and contents of vesicles associated with developing walls. Work on the mechanism of hyphal growth has been reported elsewhere (Heath, 1970).

\section{METHODS}

Vegetative subcultures of the strain of Saprolegnia ferax (Gruithuisen) Thuret isolated by Manton, Clarke \& Greenwood (I95I) were grown in the medium described by Heath \& Greenwood (1970) and induced to form zoosporangia by transfer to water. Because this strain of $S$. ferax lost the ability to form oogonia in culture we obtained Saprolegnia furcata Maurizio from the Aquatic Phycomycete Culture Collection of Reading University. This species readily produced oogonia and antheridia when grown on hemp seeds in water. Dictyuchus sterile Coker was supplied as strain 34 I c from the same source as $S$. furcata and was cultured in the same manner as S. ferax.

Material for subsequent sectioning was fixed in $(a) 2.5$ or $5 \%(\mathrm{w} / \mathrm{v})$ glutaraldehyde followed by I $\%(\mathrm{w} / \mathrm{v})$ osmium tetroxide, $(b)$ I $\%(\mathrm{w} / \mathrm{v})$ osmium tetroxide alone, and

* Present address: Department of Botany, University of Georgia, Athens, Georgia 30601, U.S.A. 
(c) $2 \%(\mathrm{w} / \mathrm{v})$ glutaraldehyde alone. All fixatives were buffered to $\mathrm{pH} 7.0$ with $\mathrm{M} / \mathrm{I} 5$ Sorenson's phosphate and were used at approximately $25^{\circ}$. All fixed material was dehydrated in an ethanol series and embedded via epoxy-propane in Epon 8I2. Unless stated otherwise, all sections illustrated were stained in $2 \%$ aqueous uranyl acetate at $60^{\circ}$ for $20 \mathrm{~min}$. followed by Reynolds's lead citrate at approximately $25^{\circ}$ for I to $7 \mathrm{~min}$. Vegetative colonies were fixed in situ on agar and all specimens were embedded flat, so that a desired structure could be selected with a light microscope and sectioned in a known orientation. Serial sectionings of individual apices enabled us to identify the median longitudinal sections.

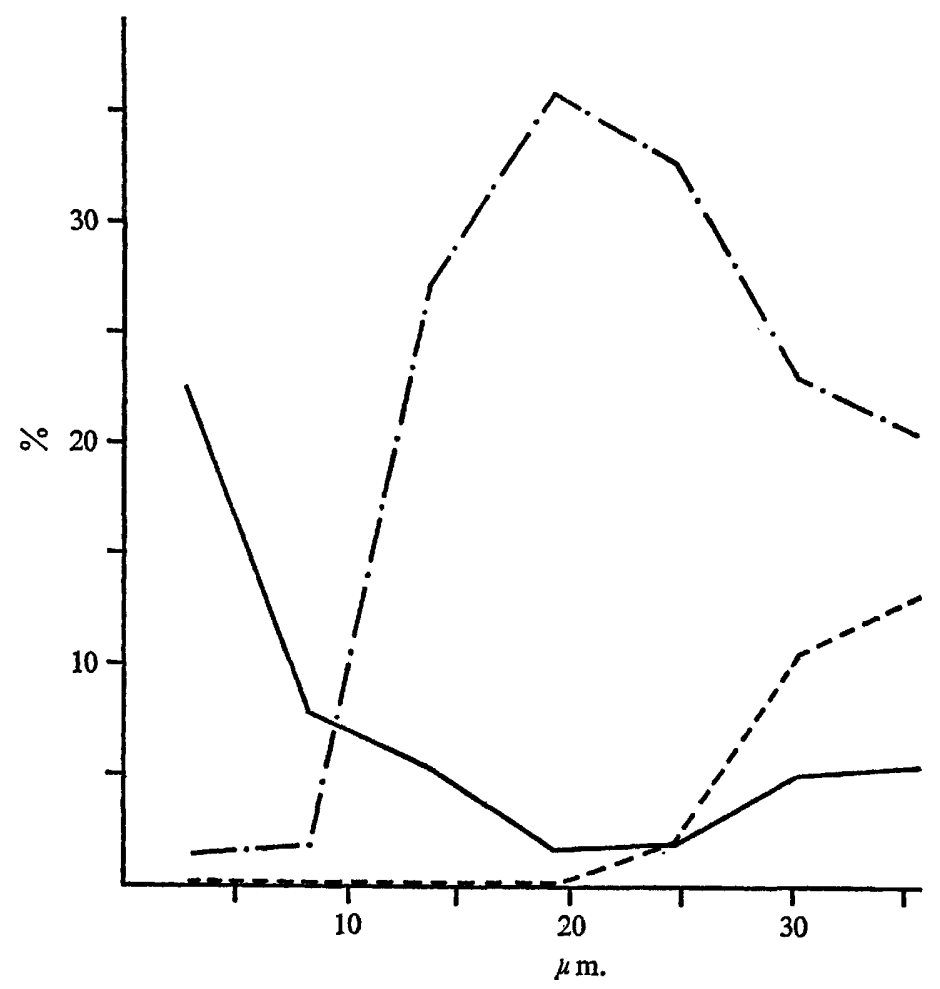

Fig. I. In order to quantify the distribution of organelles in a hyphal apex a montage of an approximately median longitudinal section was divided into seven equal arbitrary transverse segments. Each segment was covered with a grid of transverse parallel lines spaced $\mathbf{I ~ c m}$. apart. The total length of line over each category of organelle was expressed as a percentage of the total cytoplasm plus organelles transected in each segment. These values were plotted at the median point of each segment, $0 \mu \mathrm{m}$. being the apex of the hypha. - Wall vesicles; - - , mitochondria; ---, nuclei.

Frozen-etched material was fixed in $5 \%(\mathrm{w} / \mathrm{v})$ phosphate-buffered glutaraldehyde for I $\mathrm{h}$. then impregnated with $30 \%(\mathrm{v} / \mathrm{v})$ glycerol for $24 \mathrm{~h}$. It was then frozen, cleaved, etched and replicated as described by Moor \& Mühlethaler (1963).

In order to identify structures with a high polysaccharide content some sections were mounted on gold grids and treated with the periodic acid-silver hexamine stain described by Pickett-Heaps (1967). Thirty min. in I \% (v/v) periodic acid followed by 
I h. in silver hexamine, both at $60^{\circ}$, gave satisfactory results (Heath, I969). The specificity of the reaction was checked by the control procedures used by Pickett-Heaps (I967).

\section{RESULTS}

Hyphal apices. Vegetative hyphal apices of Saprolegnia ferax were typically tapering with a Io to $40 \mu \mathrm{m}$. apical region which was usually devoid of nuclei and mitochondria. Thin sections of this apical region occasionally revealed short profiles of mitochondria and some ribosome-studded endoplasmic reticulum (Pl. 2, fig. 3) but it was filled mainly with characteristic, membrane-bounded vesicles which will be termed 'wall vesicles' (Pl. I, fig. I). A typical distribution of organelles in a hyphal apex is shown in Fig. I. Whilst the wall vesicles achieved their highest concentration in the apical $5 \mu \mathrm{m}$. they were still present at a considerable distance behind the apex, where they tended to be confined to the peripheral cytoplasm adjacent to the cell walls (Pl. 4, fig. 9).

Properties of wall vesicles. The appearance of the wall vesicles varied slightly in different hyphae but they had constant characteristics for each fixation process. After glutaraldehyde-osmium they were predominantly isodiametric, with a diameter of approximately $150 \mathrm{~nm}$. but they could also be tubular (Pl. I, fig. I). This fixation revealed a fibrous granular material in the lumina of the wall vesicles (Pl. I, fig. I). Fixation in osmium alone tended to produce a more regular, spherical type of vesicle with a conspicuously clear lumen which often contained a very dark-staining globule (P1. 2, fig. 3) unlike anything detected in glutaraldehyde-osmium fixed material. Sectioned hyphae fixed in glutaraldehyde alone gave a confusing image, often with negatively contrasted membranes around the wall vesicles (Pl. 3, fig. 5). The contents of these vesicles stained strongly with uranyl acetate and lead citrate (Pl. 3, fig. 5) with a similar, but less intense, stain on Golgi cisternae (Pl. 3, fig. 6, 7). The walls were not stained in these preparations ( $\mathrm{Pl} .3$, fig. 5). Wall vesicles were also detectable after freeze-etching (Pl. 4, fig. 8) when their membranes were seen to bear a few particles, about Io $\mathrm{nm}$. diameter, similar to those occurring abundantly on the plasmalemma (Pl. 4, fig. 8 to Io).

Sections stained with periodic acid-silver hexamine after glutaraldehyde-osmium fixation (PI. I, fig. 2) showed a heavy deposit of silver grains over the cell walls and all over the wall vesicles. After fixation with osmium alone only the walls and the membranes of the wall vesicles stained strongly (Pl. 2, fig. 4); the lumina of these vesicles were conspicuously unstained.

\section{Asexual reproduction in Saprolegnia ferax}

The disposition and staining characteristics of the wall vesicles in the hyphal apices suggested that they might be involved in wall formation (see Discussion). If this hypothesis were correct it seemed likely that similar vesicles would occur at other stages in the life-cycle where wall material was being deposited. When a vegetative apex transforms into a zoosporangium, approximately the apical $200 \mu \mathrm{m}$. becomes separated from the rest of the hypha by the rapid insertion of a layered basal crosswall (Gay \& Greenwood, 1966; Heath \& Greenwood, 1970). It was found that the sporangial walls above this cross-wall expanded and became thickened by the addition of a layer of wall material which also extended across the cross-wall (Pl. 5, fig. II). 
A similar layer of material was also deposited on the hyphal side of the cross-wall. The deposition of this additional material was accompanied by periodic acid-silver hexamine positive vesicles in the adjacent cytoplasm (Pl. 5, fig. I I to I3). In addition, the apex of each sporangium extends to form a papilla which eventually breaks down to release the zoospores (Gay \& Greenwood, 1966). During their formation these papillae were filled with periodic acid-silver hexamine positive wall vesicles (Pl. 6, fig. I4, I5) which were absent from mature papillae (Pl. 6, fig. I6).

After their motile phase the zoospores encyst (Heath \& Greenwood, 197I); upon transfer to nutrient medium these cysts germinate by producing a germ tube which elongates into the first hypha of a new colony. The first indication of impending germination was a concentration of wall vesicles in the cytoplasm adjacent to the cyst wall (Pl. 6, fig. I7; Pl. 7, fig. I8). As the germ tube emerged a new wall was laid down as an extension of the inner layer of the cyst wall. Its apex contained a high concentration of wall vesicles (P1. 7, fig. 18).

\section{Asexual reproduction in Dictyuchus sterile}

In Dictyuchus sterile the early formation of the sporangium was not studied. Unlike those of Saprolegnia ferax, the zoospores of $D$. sterile were not released from the sporangium before they encysted so that many encysting spores could be observed in a suitable sporangium. During the early stages of cyst wall production the peripheral cytoplasm of the zoospores contained many wall vesicles (Pl. 7, fig. 19) which were far less abundant when the wall was fully formed. Each zoospore was released from the sporangium through a papilla which develops as an extension of the cyst wall through the sporangium wall. These papillae contained a high concentration of vesicles resembling wall vesicles (Heath \& Greenwood, 1970).

\section{Sexual reproduction in Saprolegnia furcata}

When Saprolegnia furcata underwent sexual reproduction the ends of some hyphae swelled to form spherical oogonia of up to $40 \mu \mathrm{m}$. in diameter. As in the sporangia of $S$. ferax, an increase in the thickness and extent of the wall occurred in the presence of numerous wall vesicles in the adjacent peripheral cytoplasm (Pl. 8, fig. 2I). When the oogonium achieved its mature size wall vesicles were rare in the cytoplasm (P1. 8, fig. 20). Associated hyphal branches which developed into antheridia grew towards and contacted the oogonial wall, ultimately forming fertilization tubes which penetrated the wall and grew to each oospore. The cytoplasm of the antheridia adjacent to the oogonium prior to penetration was particularly rich in wall vesicles (Pl. 8, fig. 20). Some antheridia - for example that shown in Pl. 8, fig. 20 -also showed vesicles of similar size but with contents that stained darkly after osmium tetroxide fixation and uranyl acetate and lead citrate staining.

\section{DISCUSSION}

The apex is the main site of addition of material to fungal walls (Rizvi \& Robertson, 1965; Marchant \& Smith, I968); thus the preferential accumulation of wall vesicles in this region suggests that they may be involved in wall formation. This suggestion is in agreement with the conclusions reached by Girbardt (1969) and Grove et al. (1970) for morphologically similar vesicles in other fungi. The close spatial association 
between the developing walls and similar vesicles in the sporangia and germinating zoospores of Saprolegnia ferax and the oogonia of $S$. furcata further suggests that these vesicles are involved in wall formation. Better evidence for a wall-forming role for wall vesicles is their abundance in the developing apical papilla of the zoosporangium of S. ferax and the developing oogonium of $S$. furcata, their absence in the mature papilla and oogonium, and their decline in numbers during the deposition of the cyst walls in the sporangia of Dictyuchus sterile.

In studies of other plant systems it has been suggested that the amorphous hemicellulose fraction of the wall is contributed by fusion of vesicles with the plasmalemma and the consequent release of their contents to the wall (Northcote, 1969). Since the walls of Saprolegnia species contain $49 \%$ (Novaes-Ledieu, Jiménez-Martinez \& Villanueva, 1967) to $85 \%$ (Parker, Preston \& Fogg, 1963) hemicellulose, largely in the form of glucose polymers, such material may be contained in the wall vesicles. Although not specific for polysaccharides (Hotchkiss, 1948; Pearse, 196I) it is likely that the periodic acid-silver hexamine reaction of the walls and wall vesicles after glutaraldehyde-osmium fixation is due to polysaccharide (Pickett-Heaps, 1967), thus supporting the hypothesis that the wall vesicles contribute material to the walls. However, the difference in periodic acid-silver hexamine reaction between the walls and wall vesicles after osmium fixation alone indicates non-identical constituents. This difference could be accounted for if the wall vesicles contained material of a lower molecular weight which could be lost if osmium fixation produced more permeable membranes than did glutaraldehyde. Wang \& Bartnicki-Garcia (1966) suggested that the formation of glucans from uridine diphosphate glucose (UDPG) occurs in the cell wall. These UDPG precursors may be the predominant component of the wall vesicles. Eschrich's (1962) and Reynolds's (1963) observations that organophosphates stain strongly with lead salts may account for the heavy deposits of uranyl acetate and lead citrate found after glutaraldehyde fixation.

The antheridia must ultimately break through the oogonium wall during the formation of a fertilization tube. Similarly, the germ tube must break out of the encysted spore and the sporangium wall must be breached to release the zoospores of Dictyuchus sterile. This suggests that wall-degrading enzymes must be considered as possible components of the wall vesicles in these areas, and also in the hyphae in view of the work on Achlya by Thomas \& Mullins (1969) and Rhizopus by Hawker \& Gooday (1969). The darker vesicles in Pl. 8, fig. 21 may be those containing the enzymes in the antheridia. Clearly the contents of the wall vesicles cannot be defined without isolation and characterization studies of the type performed by Van Der Woude, Morré \& Bracker (1969).

The origin of the wall vesicles is uncertain. The absence both of morphological intermediates between wall vesicles and Golgi cisternae and periodic acid-silver hexamine reactivity over the Golgi in glutaraldehyde-osmium fixed hyphae suggests that, in contrast to the reports for higher plants (Mühlethaler, 1967; Northcote, 1969), Phytophthora (Hemmes \& Hohl, 1969) and Pythium (Grove et al. 1970), wall vesicles do not originate in the Golgi apparatus. However, the uranyl acetate-lead citrate staining of the wall vesicles and Golgi cisternae after glutaraldehyde fixation supports a Golgi origin. If the Golgi system is the source of wall vesicles then the difference in periodic acid-silver hexamine reactivity of the cisternae and wall vesicles after glutaraldehyde-osmium fixation clearly indicates a change in the content of the vesicles 
after they leave the Golgi system; a finding comparable with that of Van Der Woude et al. (1969) in pollen tubes.

We should like to thank the Science Research Council for financial support during the course of this work, Miss Marion Martin for technical assistance, and Dr H. C. Aldrich for the use of his freeze-etch facilities.

\section{REFERENCES}

BRENNER, D. M. \& CARRoll, G. C. (1968). Fine structural correlates of growth in hyphae of Ascodesmis sphaerospora. Journal of Bacteriology 95, 658-671.

GAY, J. L. \& Greenwood, A. D. (1966). Structural aspects of zoospore production in Saprolegnia ferax with particular reference to the cell and vesicular membranes. Colston Papers 18, 95IIO.

EscHRICH, W. (1962). Uber die Darstellung organischer Phosphatverbindung im Electronen mikroskop. Protoplasma 56, 371-373.

GirbardT, M. (1969). Die Ultrastruktur der Apikalregion von Pilzhyphen. Protoplasma 67, 4I 3-44I.

Grove, S. N., Bracker, C. E. \& MorRÉ, D. J. (1970). An ultrastructural basis for hyphal tip growth in Pythium ultimum. American Journal of Botany 57, 245-266.

HAwKer, L. E. \& GoodAy, M. A. (1969). Fusion, subsequent swelling and final dissolution of the apical walls of the progametangia of Rhizopus sexualis (Smith) Callen: an electron microscope study. New Phytologist 68, I33-140.

HeAtH, I. B. (1969). Structural Aspects of the Growth and Reproduction of Saprolegnia spp. Ph.D. thesis, University of London.

Heath, I. B. (1970). Hyphal growth in Saprolegnia. American Journal of Botany 57, 745 (Abstr.).

HeAth, I. B. \& GREENWOOD, A. D. (1970). The structure and formation of lomasomes. Journal of General Microbiology 62, 129-137.

HeATH, I. B. \& Greenwood, A. D. (1971). Ultrastructural observations on the kinetosomes, Golgi bodies and cysts during the asexual life cycle of Saprolegnia. Zeitschrift für Zellforschung und mikroskopische Anatomie 112, 371-389.

Hemmes, D. E. \& HoHL, H. R. (1969). Ultrastructural changes in directly germinating sporangia of Phytophthora parasitica. American Journal of Botany 56, 300-313.

HotchKIss, R. D. (1948). A microchemical reaction resulting in the staining of polysaccharide structures in fixed tissue preparations. Archives of Biochemistry I6, I3I-I39.

Manton, I., Clarke, B. \& Greenwood, A. D. (I95I). Observations with the electron microscope on a species of Saprolegnia. I. Journal of Experimental Botany 2, 32I-33I.

MARChANT, R. \& SMith, D. G. (I968). A serological investigation of hyphal growth in Fusarium culmorum. Archiv für Mikrobiologie 62, 237-250.

McCluRe, W. K., PARK, D. \& Robinson, P. M. (I968). Apical organization in the somatic hyphae of fungi. Journal of General Microbiology 50, 177-182.

MOOR, H. \& MÜHLETHALER, K. (1963). The fine structure in frozen-etched yeast cells. Journal of Cell Biology I7, 609-628.

MüHLETHALER, K. (1967). Ultrastructure and formation of plant cell walls. Annual Review of Plant Physiology 18, I-24.

NorTHCOTE, D. H. (1969). Fine structure of cytoplasm in relation to synthesis and secretion in plant cells. Proceedings of the Royal Society of London B 173, 2I-30.

Novaes-Ledieu, M., Jiménez-Martínez, A. \& Villanueva, J. R. (I967). Chemical composition of hyphal wall of Phycomycetes. Journal of General Microbiology 47, 237-245.

Parker, B. C., Preston, R. D. \& FogG, G. E. (1963). Studies of the structure and chemical composition of the cell walls of Vaucheriaceae and Saprolegniaceae. Proceedings of the Royal Society of London B 158, 435-445.

PeARSE, A. G. E. (1961). Histochemistry, Theoretical and Applied, 2nd edn. London: Churchill.

Picketr-Heaps, J. D. (1967). Preliminary attempts at ultrastructural polysaccharide localization in root tip cells. Journal of Histochemistry and Cytochemistry 15, 442-455.

REYNoLDS, E. S. (1963). The use of lead citrate at high $\mathrm{pH}$ as an electron-opaque stain in electron microscopy. Journal of Cell Biology 17, 208-212. 
Rizvi, S. R. H. \& Robertson, N. F. (1965). Apical disintegration of hyphae of Neurospora crassa as a response to L-sorbose. Transactions of the British Mycological Society 48, 469-477.

Thomas, D. Des S. \& Muluins, J. T. (I969). Cellulase induction and wall extension in the water mould Achlya ambisexualis. Physiologia Plantarum 22, 347-353.

Van Der Woude, W. J., Morré, D. J. \& Bracker, C. E. (I969). A role for secretory vesicles in polysaccharide biosynthesis. Abstracts of the IIth International Botanical Congress, Seattle, Washington.

WANG, M. C. \& BARTNiCKI-Garcia, S. (1966). Biosynthesis of $\beta$-I,3- and $\beta$-1,6-linked glucan by Phytophthora cinnamomi hyphal walls. Biochemical and Biophysical Research Communications 24, 832-837.

\section{EXPLANATION OF PLATES}

Key to symbols: $\mathrm{Ga}$, fixed in glutaraldehyde alone; $\mathrm{Ga} / \mathrm{Os}$, fixed in glutaraldehyde followed by osmium tetroxide; Os, fixed in osmium tetroxide alone; $a$, antheridium; er, endoplasmic reticulum; $G$, Golgi body; $h$, hypha; $l$, lomasome; $m$, mitochondrion; $h$, nucleus; $o$, oogonium; $s$, sporangium; $v$, wall vesicles; $w$, cell wall; $w_{a}$, antheridium wall; $w_{o}$, oogonium wall; $\times w$, cross-wall.

\section{Plate I}

Fig. 1. Saprolegnia ferax. Median longitudinal section of a vegetative hyphal apex after glutaraldehydeosmium fixation. There are abundant vesicles with granular contents, short profiles of endoplasmic reticulum and lomasomes. The large vesicle at the apex (arrowed) is an atypically large lomasome. $\mathrm{Ga} / \mathrm{Os} . \times 30,100$.

Fig. 2. S. ferax. A similar section to that shown in fig. I treated with the periodic acid-silver hexamine stain. Whilst there is a general deposit of silver over the cytoplasm, the wall vesicles (arrowed) and cell wall have a heavier deposit. $\mathrm{Ga} / \mathrm{Os} . \times 3 \mathrm{I}, 300$.

\section{Plate 2}

Fig. 3. Saprolegnia ferax. Portion of a median longitudinal section of a hyphal apex fixed in osmium tetroxide alone. The wall vesicles are more spherical and apparently empty except for the electronopaque globules arrowed. Such globules may be a condensed form of the material in the vesicles seen in Pl. I, fig. I. Os. $\times 34,400$.

Fig. 4. S. ferax. A similar apex to fig. 3 treated with the periodic acid-silver hexamine reagents. The wall is heavily stained but the lumina of the wall vesicles are conspicuously free of stain, only their membranes are overlain by silver grains. Os. $\times 33,900$.

\section{Plate 3}

Fig. 5. Saprolegnia ferax. A median longitudinal section of a hyphal apex. The wall vesicles stain densely with uranyl acetate and lead citrate (arrows). The inset shows details of some of the wall vesicles; note negatively contrasted membrane. Ga. $\times 23,400$; inset, $\times 64,500$.

Fig. 6. S. ferax. Heavy lead and uranium stain deposit on cisternae and vesicles of a Golgi body in a glutaraldehyde fixed hypha. Ga. $\times 50,600$.

Fig. 7. S. ferax. Heavy stain deposit on cisternae and vesicles of a Golgi body after glutaraldehyde fixation and uranyl acetate, lead citrate stain. A low-magnification micrograph showed that this Golgi body had its forming face adjacent to a nuclear envelope. Ga. $\times 87,400$.

\section{Plate 4}

Fig. 8. Saprolegnia ferax. A replica of a median longitudinal fracture of a frozen-etched hyphal apex. Some wall vesicles have particles on their surface (arrows). Ga. $\times 40,200$.

Fig. 9. S. ferax. Sub-apical region of a frozen-etched hypha showing wall vesicles adjacent to the wall. Note the particles on the surface of the vesicles. Ga. $\times 92,000$.

Fig. 10. S. ferax. View of a frozen-etched, near-apical plasmalemma, showing abundant particles. Ga. $\times 114,400$. 


\section{Plate 5}

Fig. I I. Saprolegnia ferax. A longitudinal section of a portion of the cross-wall at the base of a developing zoosporangium. The original hyphal wall $\left(w_{1}\right)$ is being thickened by the addition of a layer of wall material $\left(w_{2}\right)$ which lines both sides of the cross-wall and extends along the old wall. There are abundant wall vesicles concentrated around the site of development of this wall. Ga/Os. $\times 39,100$.

Fig. 12. S. ferax. Numerous wall vesicles adjacent to the lateral wall of a developing zoosporangium. Ga/Os. $\times 60,800$.

Fig. 13. S. ferax. Comparable structures to fig. I2 showing the periodic acid-silver hexamine reaction over the cell wall and wall vesicles. $\mathrm{Ga} / \mathrm{Os} . \times 49,100$.

\section{Plate 6}

Fig. 14. Saprolegnia ferax. Portion of a developing zoosporangium, showing the high concentration of wall vesicles in the apical papilla. Ga/Os. $\times 22,200$.

Fig. I5. S. ferax. Similar structure to that shown in fig. I4 but containing fewer vesicles. The vesicles and wall are periodic acid-silver hexamine positive. Ga/Os. $\times 23,100$.

Fig. I6. $S$. ferax. Near-mature apical papilla, showing very few wall vesicles relative to fig. I4. $\mathrm{Ga} / \mathrm{Os.} \times 17,000$.

Fig. 17. S. ferax. Encysted primary zoospore at an early stage in germination. There is a high concentration of wall vesicles in the tip of the germ tube. Ga/Os. $\times$ I 1,700.

\section{Plate 7}

Fig. I8. Saprolegnia ferax. A high concentration of vesicles at the tip of a slightly longer germ tube than that shown in fig. I7. Ga/Os. $\times 33,300$.

Fig. 19. Dictyuchus sterile. Portions of three primary zoospores beginning to encyst within a zoosporangium. The walls of the cysts are very thin and the cytoplasm contains wall vesicles concentrated adjacent to the plasmalemma. Ga/Os. $\times 22,900$.

\section{Plate 8}

Fig. 20. Saprolegnia furcata. Part of an antheridium applied to the surface of a post-cleavage oogonium. The antheridium is still developing and contains wall vesicles which are most abundant at the periphery. Within the oogonium the oosphere has a very thin wall and few wall vesicles. The oogonium wall $\left(w_{o}\right)$ is considerably thicker than at the earlier stage (fig. 21 ). Ga/Os. $\times 33,390$.

Fig. 21. S. furcata. Portion of the periphery of a developing oogonium, showing numerous wall vesicles adjacent to the wall. Ga/Os. $\times 46,500$. 

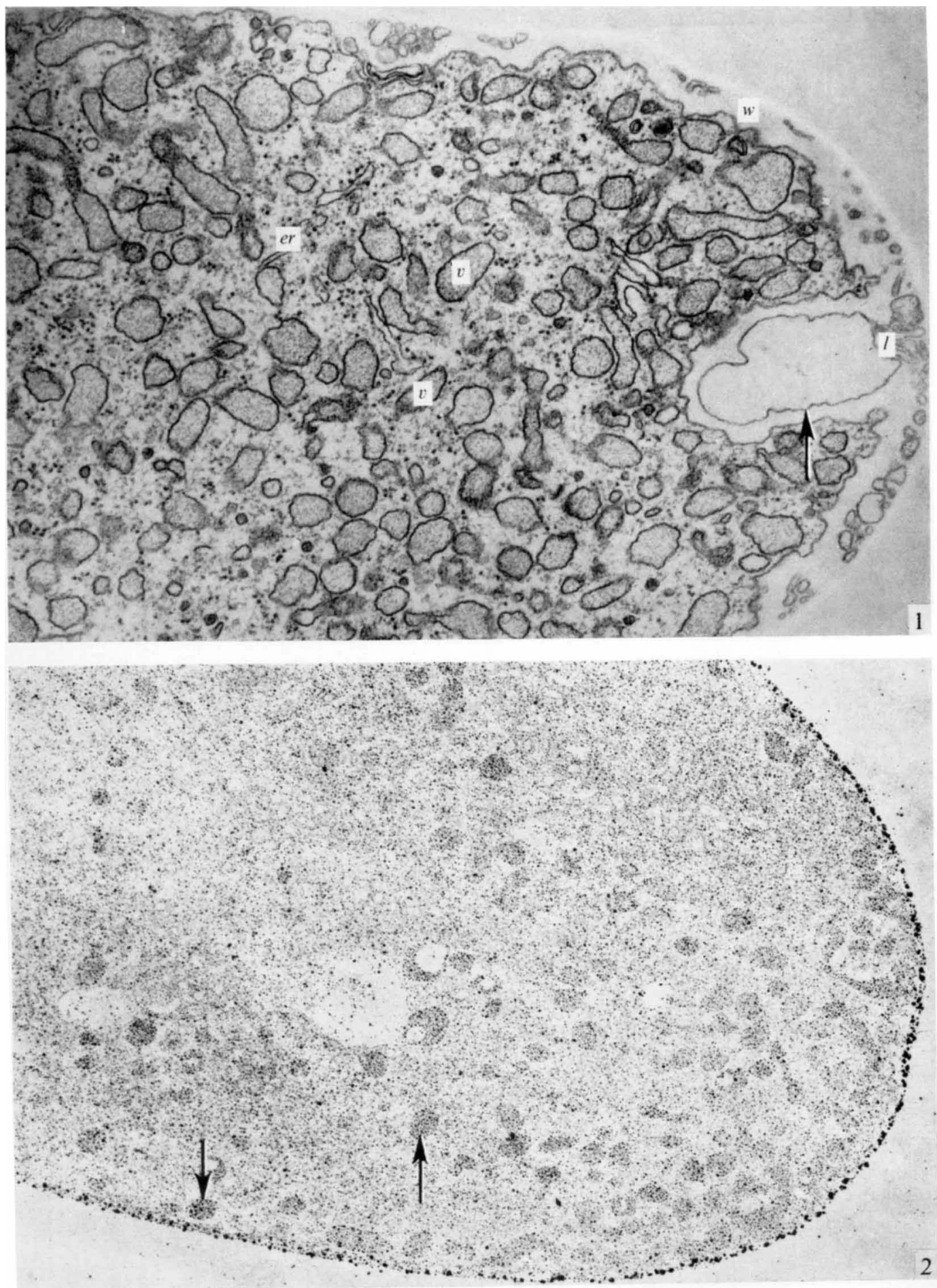
Journal of General Microbiology, Vol. 65, No. 2

Plate 2
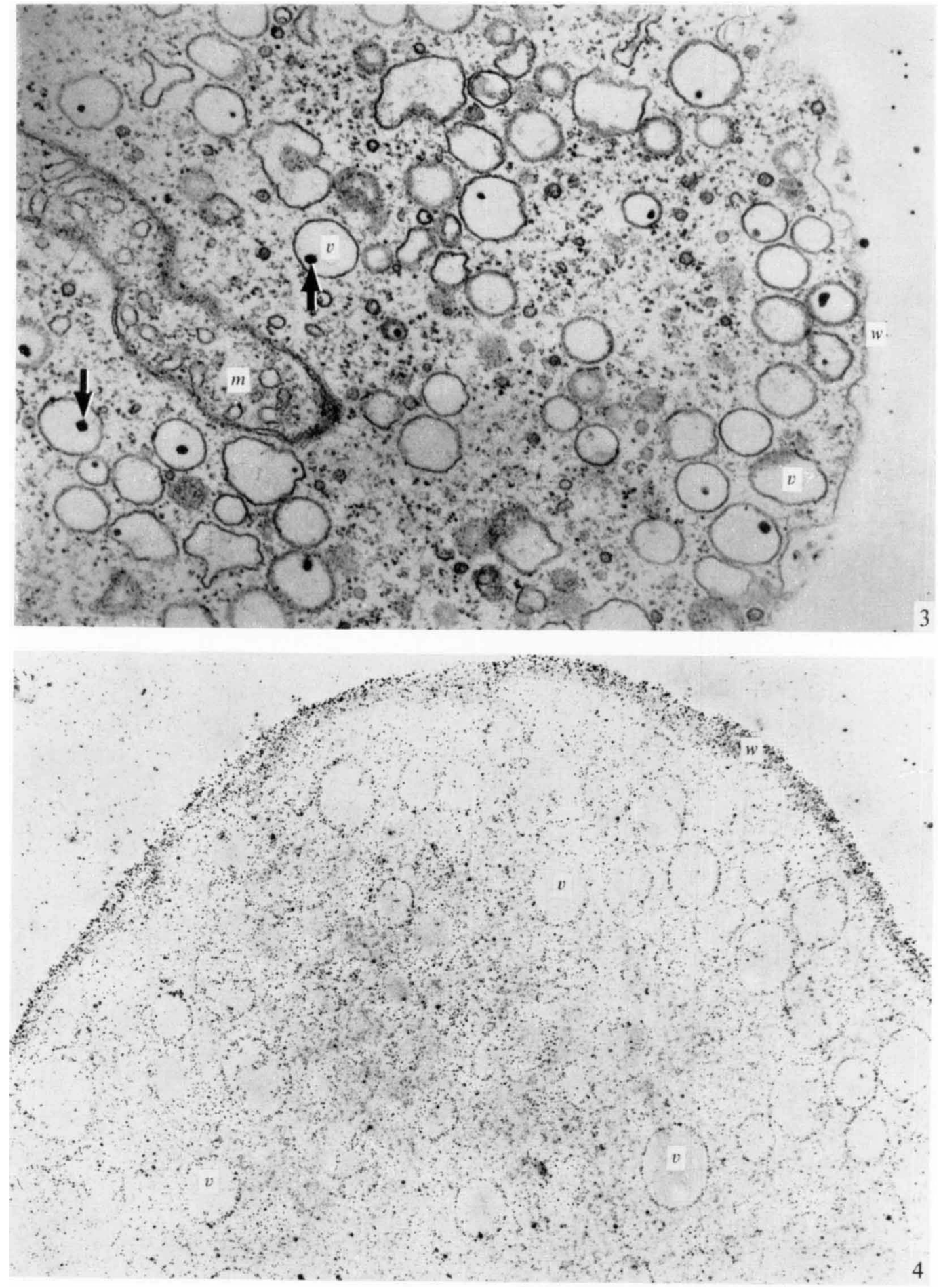

I. B. HEATH, J. L. GAY AND A. D. GREENWOOD 

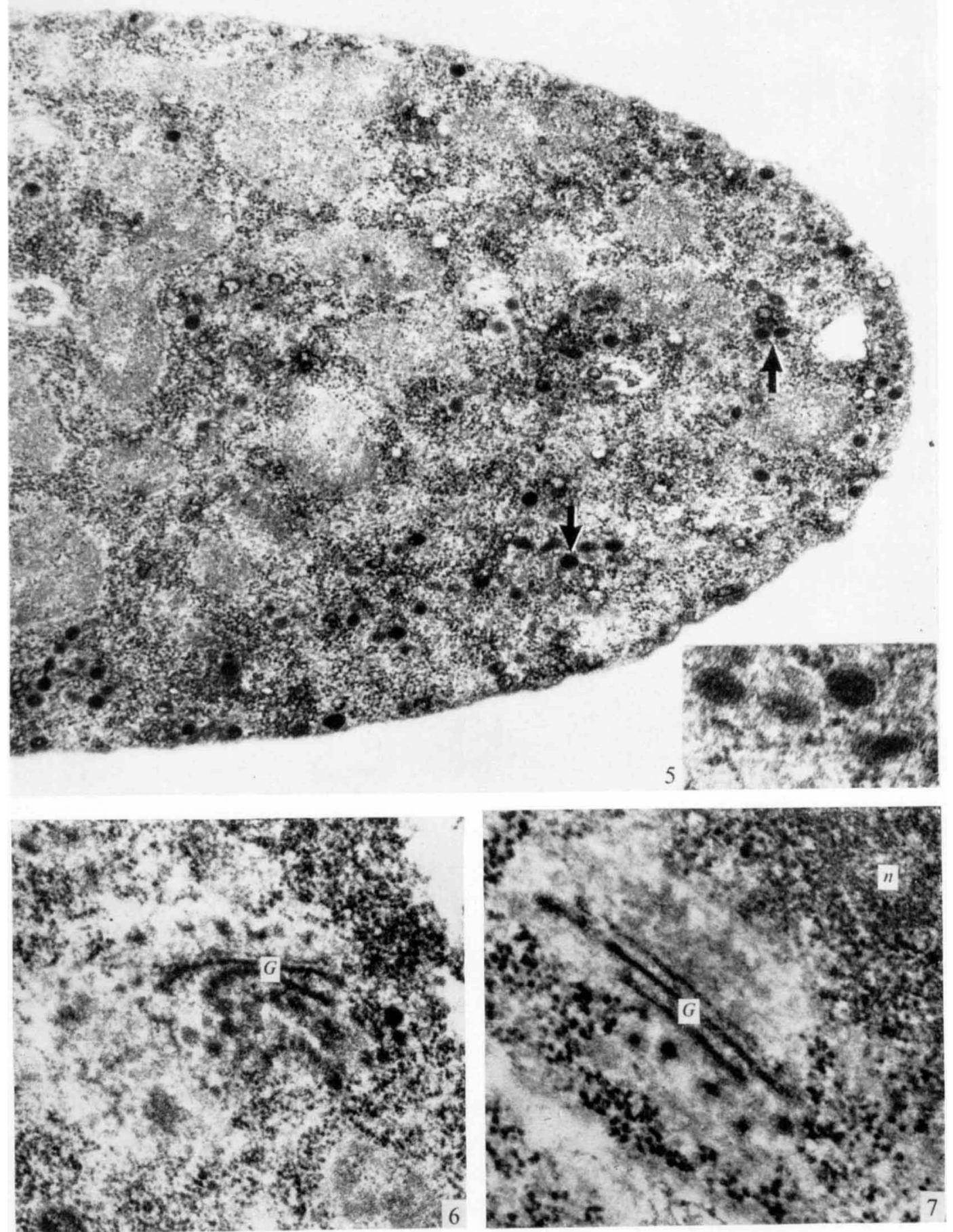

I. B. HEATH, J. L. GAY AND A. D. GREENWOOD 


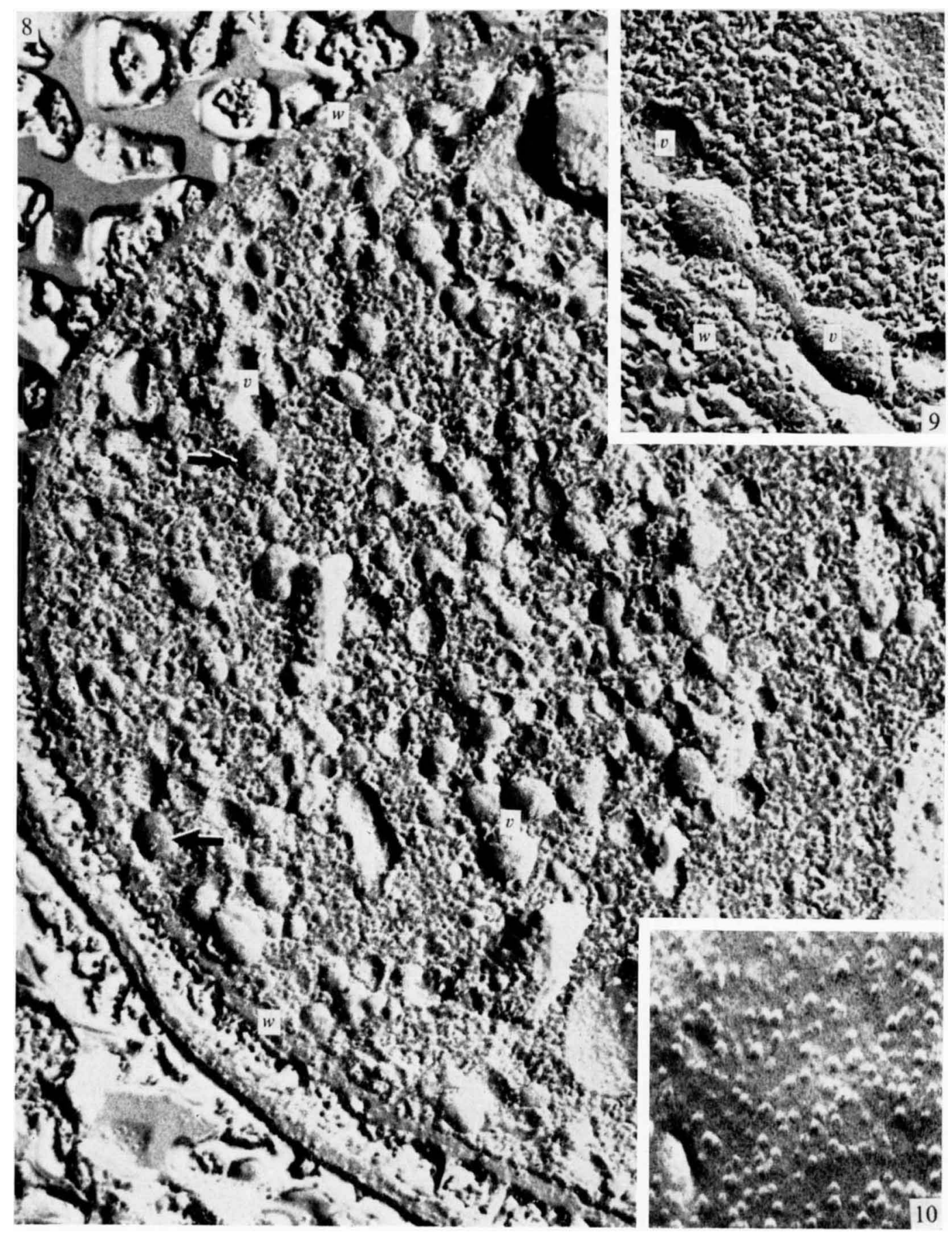



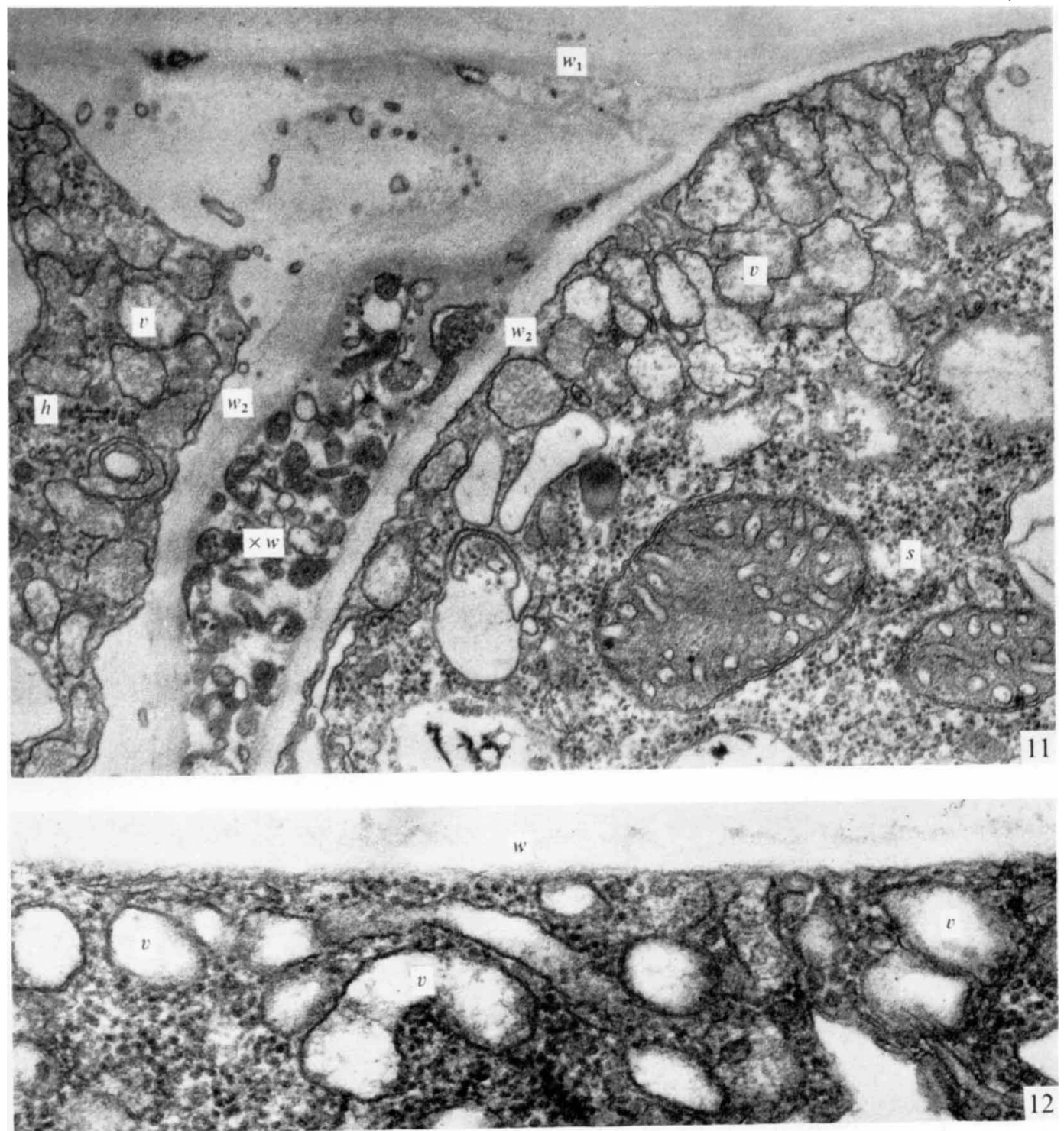

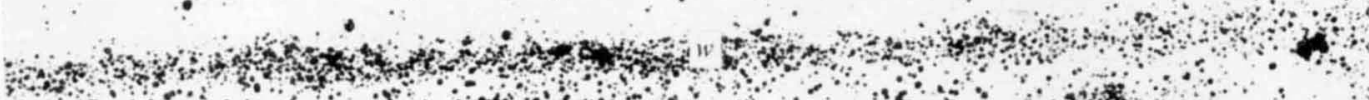

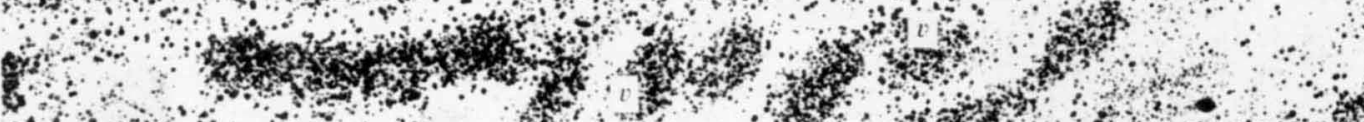

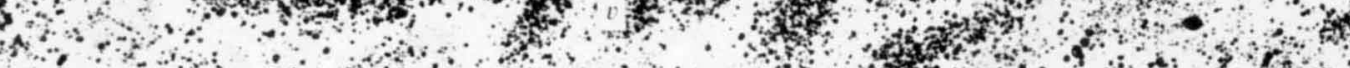

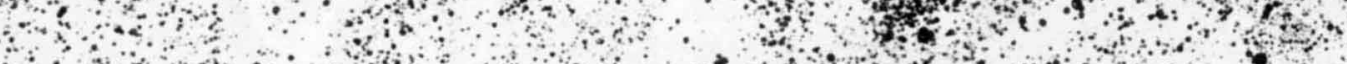

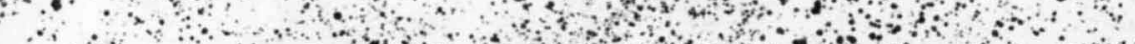

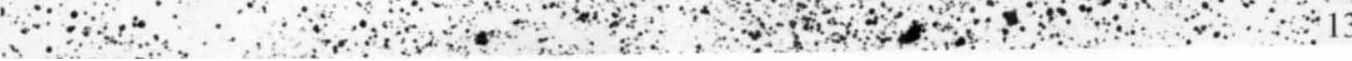

I. B. HEATH, J. L. GAY AND A. D. GREENWOOD 
Journal of General Microbiology, Vol. 65, No. 2

Plate 6
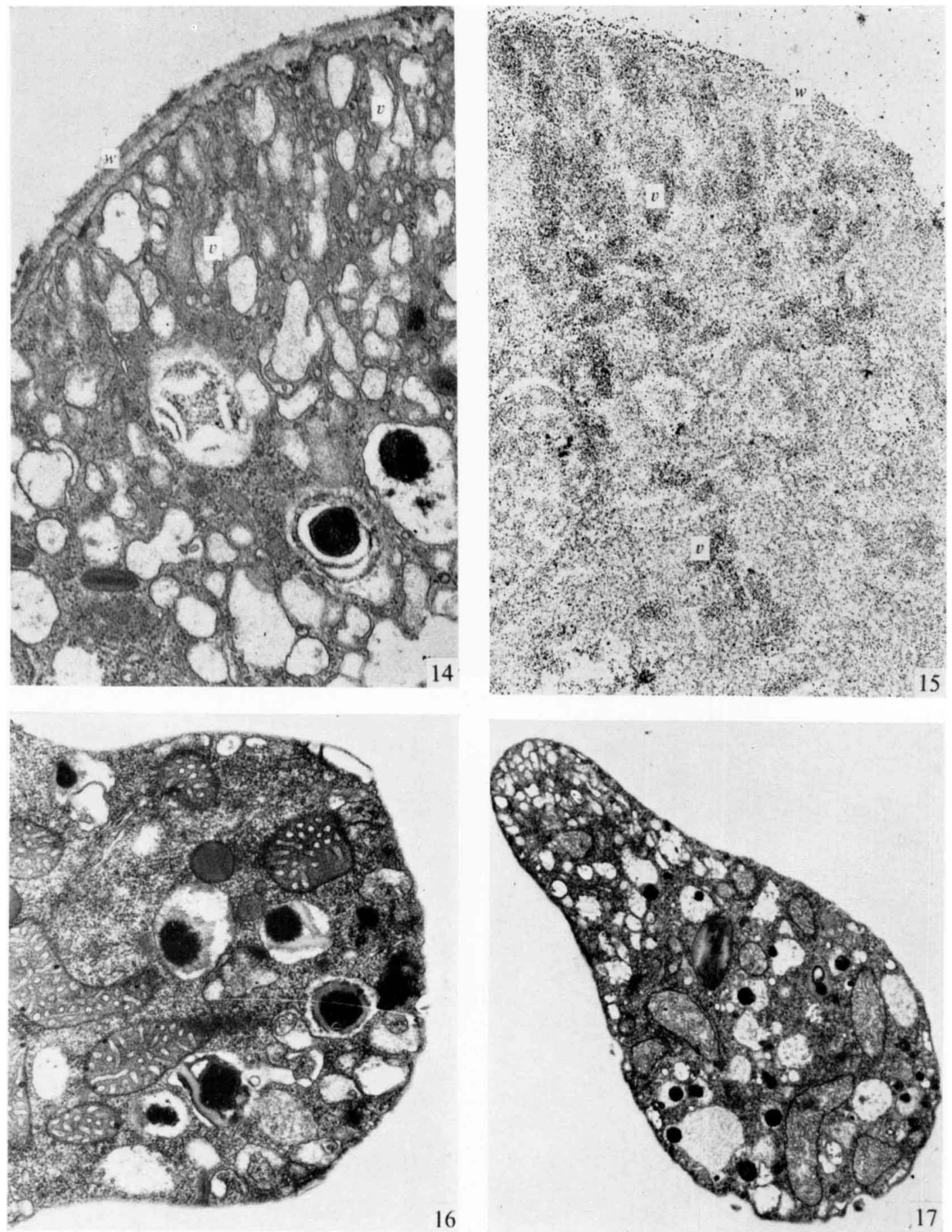

I. B. HEATH, J. L. GAY AND A. D. GREENWOOD 

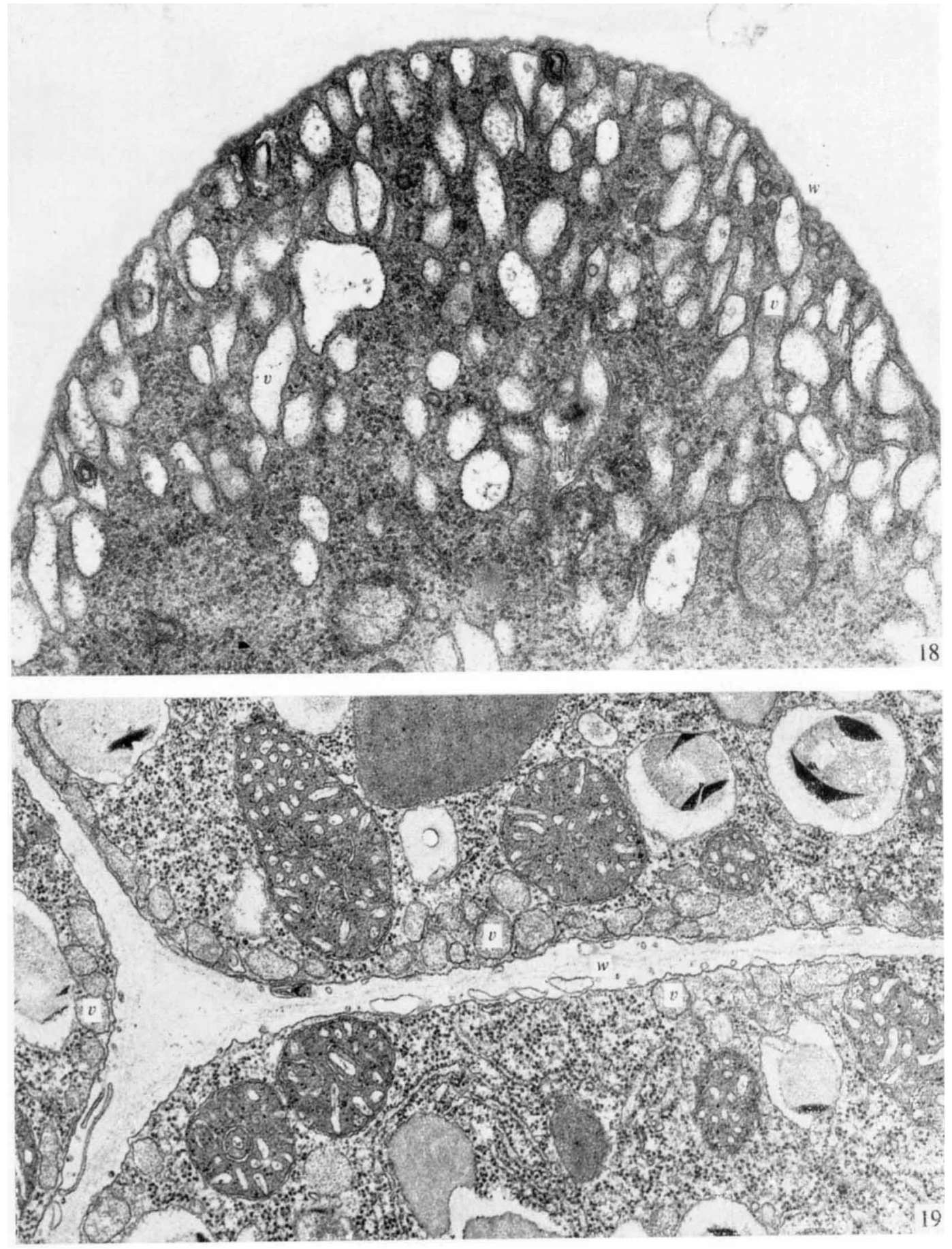

I. B. HEATH, J. L. GAY AND A. D. GREENWOOD 

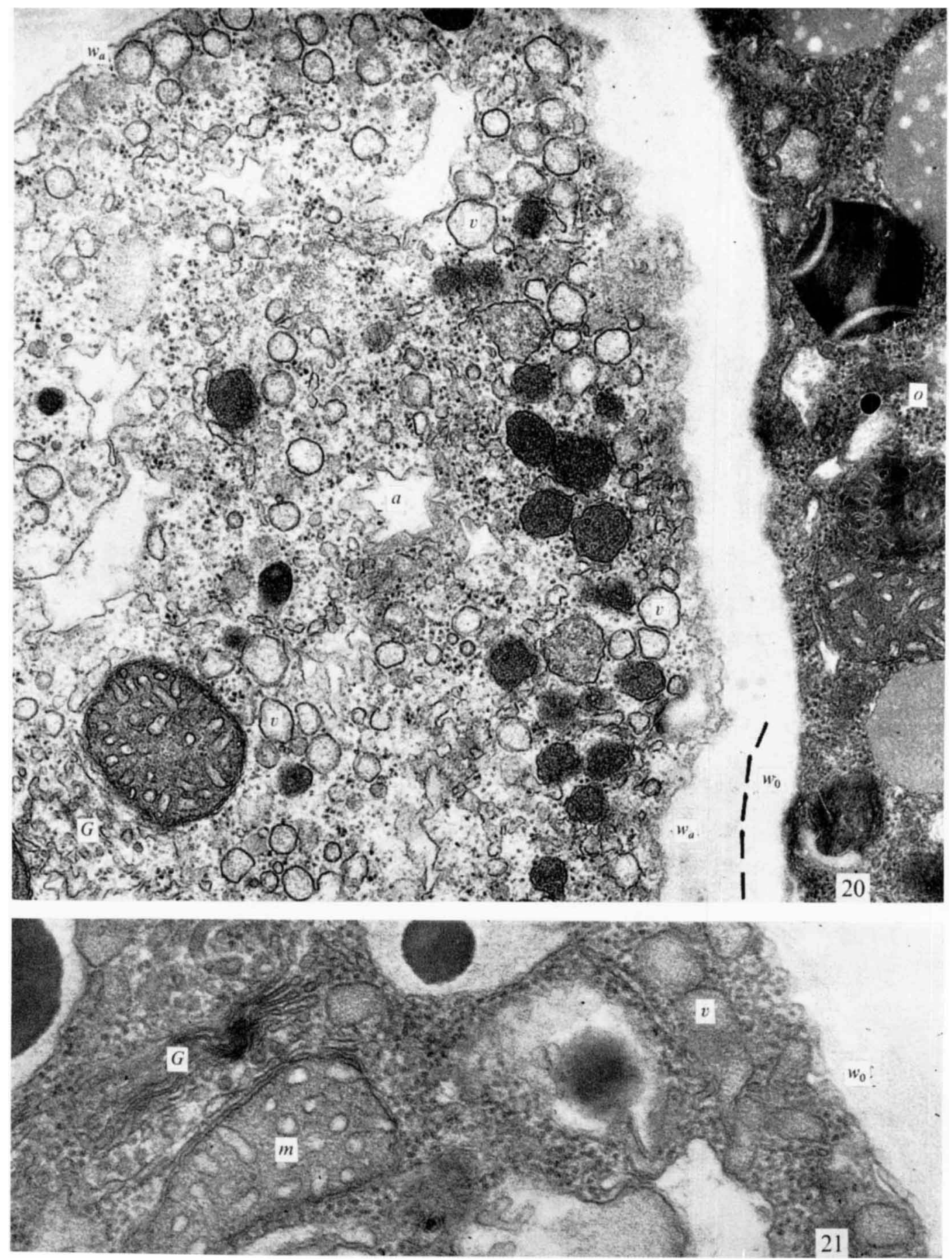

1. B. HEATH, J. L. GAY AND A. D. GREENWOOD 